\title{
Lack of association between the methylenetetrahydropholate reductase gene A1298C polymorphism and neural tube defects in a Turkish study group
}

S.H. Yildiz ${ }^{*}$, M. Ozdemir Erdogan ${ }^{1}$, M. Solak ${ }^{1}$, O. Eser $^{2}$, E S. Arkan Terzi B. Eser ${ }^{3}$, V. Kocabaş ${ }^{4}$ and A. Aslan ${ }^{5}$

${ }^{1}$ Department of Medical Genetics, Faculty of Medicine, Afyon Kocatepe University, Afyonkarahisar, Turkey

${ }^{2}$ Department of Surgical Sciences, Faculty of Medicine, Balikesir University, Balikesir, Turkey

${ }^{3}$ Department of Medical Genetics, Faculty of Medicine, Balikesir University, Balikesir, Turkey

${ }^{4}$ Department of Biochemistry, Meram Medical Faculty, Selcuk University, Konya, Turkey

${ }^{5}$ Department of Neurosurgery, Faculty of Medicine, Afyon Kocatepe University, Afyonkarahisar, Turkey

Corresponding author: S.H. Yildiz

E-mail: handanstarr@gmail.com

Genet. Mol. Res. 15 (2): gmr.15028051

Received November 12, 2015

Accepted January 18, 2016

Published June 3, 2016

DOI http://dx.doi.org/10.4238/gmr.15028051

ABSTRACT. The etiology underlying neural tube defects (NTDs) is not fully understood and is believed to involve a complex milieu of genetic and environmental factors. The A1298C polymorphism in the methylenetetrahydropholate reductase gene (MTHFR) has been associated with mild risk for NTDs. In this study, the genotype distribution of the MTHFR gene A1298C polymorphism and the levels 
of serum homocysteine, vitamin B12, and folate were evaluated in 33 children with NTDs, their mothers, and 46 healthy controls. Genotyping of the A1298C polymorphism was performed by real-time polymerase chain reaction. The $\mathrm{A}$ and $\mathrm{C}$ allele frequencies in children with NTDs and their mothers were similar to controls $(\mathrm{P}=0.160)$. The 1298AA and $1298 \mathrm{CC}$ genotype frequencies $(\mathrm{P}=0.551$ and 0.062 , respectively) in children with NTDs and their mothers did not differ from controls. On the other hand, the 1298AC genotype frequencies in children with NTDs and their mothers were significantly different from controls $(\mathrm{P}=$ 0.025). The genotype frequency of $1298 \mathrm{AC}$ was lower in children with NTDs than in controls. There was no significant association between clinical distribution of NTDs and 1298AA/AC/CC genotypes (P > 0.05). Serum vitamin B12 levels were higher in children with NTDs than their mothers and controls $(\mathrm{P}=0.001)$. There were no differences among serum homocysteine and folate levels in all groups $(\mathrm{P}=0.494$ and 0.141 , respectively). Both genetic and nutritional factors are important in the etiology of NTDs. Thus, the A1298C polymorphism cannot be regarded as a major risk factor for NTDs.

Key words: MTHFR; A1298C; Polymorphism; Neural tube defects

\section{INTRODUCTION}

Neural tube defects (NTDs) are congenital malformations of the brain and spinal cord in neurulation that occur between 21 and 28 days after conception (Christianson, 2006). Anencephaly, encephalocele, and meningomyelocele which are commonly called spina bifida, are the most common and severe forms of the NTDs (De Marco et al., 2000) and affect approximately 3 per 1000 live births in Turkey (Aydinli et al., 1998; Tunçbilek et al., 1999). The cause of NTD is assumed to be multifactorial, involving a large number of unclear genetic and environmental interactions (Copp et al., 1990).

Folate deficiency is one contributor to the etiology of NTDs, and this metabolic pathway has been the basis for many candidate gene studies (Boyles et al., 2005). The current experimental concept related to folate metabolism focuses on the role of methylation in neural tube closure (Afman et al., 2005; Blom et al., 2006; Dunlevy et al., 2006; van der Linden et al., 2008). Polymorphisms in the folate metabolism genes may play an important role in increasing susceptibility for NTDs (Barber et al., 1999). Methylenetetrahydrofolate reductase plays a central role in the metabolism of folate (Perez et al., 2003). Two common polymorphisms, C677T and A1298C, of the MTHFR gene show decreased enzyme activity and have been independently associated with NTD (Gonzalez-Herrera et al., 2007). Furthermore, it has been reported that the A1298C polymorphism in the MTHFR gene has been associated with MTHFR deficiency and mild risk for NTDs. Homozygosity for this polymorphism results in decreased enzyme activity (van der Put et al., 1998; Weisberg et al., 1998). Decreased enzyme activity usually leads to a significant reduction in plasma concentrations of folate, vitamin B12, and methionine, while levels of homocysteine are increased. The effects of the MTHFR polymorphisms on the proper function of the enzyme can be reversed by additional folic acid intake (Eskes, 1998). Periconceptional folic acid supplementation substantially reduces the 
risk of NTD-affected pregnancies (MRC Vitamin Study Research Group, 1991). The risk of recurrent NTDs is decreased in women who take folic acid or multivitamins during the periconceptional period (Czeizel and Dudas, 1992).

In this study, we investigated the plasma concentrations of folate, vitamin $\mathrm{B} 12$, and homocysteine in mothers and the distribution of the A1298C MTHFR gene polymorphism in Turkish children with NTDs.

\section{MATERIAL AND METHODS}

\section{Patient population}

We studied 33 children with NTDs (aged 6 days to 11 years) and their mothers (N $=26,20-39$ years old). Both were seen at the Afyonkarahisar Kocatepe University Hospital (Afyonkarahisar, Turkey). Of 33 children with NTDs, 13 were female and 20 were male. None of the mothers had used folic acid preconceptionally. No additional factors associated with NTD, such as exposure to radiation, anticonvulsant medication, chemical substances, or diabetes mellitus, were identified in any of the subjects. The control group consisted of 48 unrelated healthy individuals from the same region (aged 1 to 40 years). Clinical distribution of lesions in children with NTD is presented in Table 1. All participants (or their responsible next of kin) provided written informed consent and were studied under a protocol approved by the Afyon Kocatepe University Medical Ethics Committee.

Table 1. Distribution of lesions between AA/AC/CC genotypes.

\begin{tabular}{l|c|c|c|c}
\hline \multirow{2}{*}{ Type of lesion } & \multicolumn{2}{|c|}{ Genotype } & \multirow{2}{*}{ P value } \\
\cline { 2 - 5 } & AA & AC & CC & NS \\
\hline Myelomeningocoele (N) & 6 & 2 & 6 & NS \\
\hline Meningocoele (N) & 2 & - & 5 & NS \\
\hline Spina bifida oculta (N) & 5 & - & 3 & NS \\
\hline Encephalocoele (N) & 2 & - & 3 \\
\hline
\end{tabular}

$\mathrm{NS}=$ not significant.

\section{Biochemical analysis}

To prepare serum, whole blood was directly drawn into a Vacutainer® serum tube that contained no anti-coagulant. Blood was allowed to clot at $4^{\circ} \pm 2^{\circ} \mathrm{C}$ for $15-20 \mathrm{~min}$ and promptly centrifuged at $2000 \mathrm{~g}$ for $10 \mathrm{~min}$ at $4^{\circ} \pm 2^{\circ} \mathrm{C}$. Serum samples were stored at $-80^{\circ} \mathrm{C}$ until analysis.

Homocysteine levels in serum samples were quantified with the use of a Siemens Dade Behring BN* II Nephelometer (USA) according to the manufacturer protocol. In vitro diagnostic reagents for the quantitative determination of total homocysteine in human serum were done using particle enhanced immunonephelometry with BN* II System. The concentration of homocysteine is expressed as $\mu \mathrm{M}$. Serum vitamin B12 levels were quantified with the use of a Beckman Coulter Access ${ }^{\circledR}$ Immunoassay System (USA). The Access Vitamin B12 assay is a paramagnetic particle, chemiluminescent immunoassay for the quantitative determination of Vitamin B12 levels in human serum using the Access Immunoassay Systems. Data are presented as $\mathrm{pg} / \mathrm{mL}$. The levels of serum folate were quantified with the use of an ARCHITECT $^{\circledR}$ System (Abbott Laboratories, USA). The ARCHITECT folate assay uses chemiluminescent microparticle folate binding protein assay for the quantitative determination 
of folate in serum. It is a two-step assay to determine the presence of folate in human serum using chemiluminescent microparticle immunoassay (CMIA) technology with flexible assay protocols referred to as Chemiflex ${ }^{\mathrm{TM}}$ (Applied Biosystems, USA). Two pre-treatment steps mediate the release of folate from endogenous folate binding proteins. The levels of folate are presented as $\mathrm{ng} / \mathrm{mL}$.

\section{Genetic analysis}

Genomic DNA was extracted from a $200-\mu \mathrm{L}$ peripheral blood sample using a High Pure Template Preparation kit (Roche Diagnostics, Indianapolis, IN, USA). DNA quantity and purity were assessed for each sample using a Nanodrop ND-1000 spectrophotometer V 3.7 (Thermo, USA). DNA samples were stored at $-20^{\circ} \mathrm{C}$ until use. LightCycler ${ }^{\circledR}$ (Roche Diagnostics), FastStart ${ }^{\text {PLUS }}$ DNA Master Hybridization Probes (Roche Diagnostics), LightMix ${ }^{\circledR}$ (TIB MOLBIOL, Berlin, Germany), and LightCycler ${ }^{\circledR}$ Instrument 1.2 (Roche, Germany) were used for analyzing the A1298C polymorphism of the MTHFR gene. With this technology, realtime detection of the specific product followed by detection of the mutation by identification of the melting behavior of one of the two hybridization oligonucleotides was facilitated. A 163-bp fragment of the MTHFR gene was amplified with specific primers and detected with probes labeled with LightCycler ${ }^{\text {B }}$ Red 640 (Roche, Germany) (detected in channel 640). The polymorphism was determined by running a melting curve with a specific melting point $(\mathrm{Tm})$ of $59.0^{\circ} \mathrm{C}\left( \pm 1.5^{\circ} \mathrm{C}\right)$ for the mutant and $65.0^{\circ} \mathrm{C}\left( \pm 1.5^{\circ} \mathrm{C}\right)$ for the wild-type in channel 640 . The supplied positive control allowed for the verification of the experiment (TIB MOLBIOL). The cycling conditions for MTHFR were initial denaturation at $95^{\circ} \mathrm{C}$ for $10 \mathrm{~min}$, followed by 40 cycles of $95^{\circ} \mathrm{C}$ for $5 \mathrm{~s}, 62^{\circ} \mathrm{C}$ for $10 \mathrm{~s}$, and $72^{\circ} \mathrm{C}$ for $6 \mathrm{~s}$ with a ramping time of $20^{\circ} \mathrm{C} / \mathrm{s}$. After amplification, melting curves were generated by denaturation of the reaction at $95^{\circ} \mathrm{C}$ for $20 \mathrm{~s}$, holding the sample at $40^{\circ} \mathrm{C}$ for $20 \mathrm{~s}$ and then slowly heating the sample to $85^{\circ} \mathrm{C}$ with a ramp rate of $0.2^{\circ} \mathrm{C} / \mathrm{s}$ and simultaneous monitoring of fluorescence decline. LightCycler technology is a homogenous system that minimizes polymerase chain reaction (PCR) contamination concerns due to sample handling (closed capillaries throughout the PCR and detection process) and does not require digestion of PCR products with restriction enzymes and/or separation of fragments on gels.

\section{Statistical analysis}

Statistical analyses were performed using SPSS for Windows (Version 13.0, SPSS Inc., Chicago, IL, USA). A chi-square test was used to compare allele frequencies and genotypes for the 1298AA/AC/CC position in the MTHFR gene between children with NTDs, their mothers, and healthy individuals. To evaluate the effect of the mutation on the variation of biochemical parameters, a one-way analysis of variance was performed. Tukey's honest significant different test was used for intra-group comparisons. Statistical significance was established at $\mathrm{P}<0.05$.

\section{RESULTS}

Table 2 shows the genotype distribution and the relative allele frequencies for the MTHFR gene A1298C polymorphism in children with NTDs, their mothers, and healthy controls. A and C allele frequencies in children with NTDs and their mothers were similar to 
what was observed in controls $(\mathrm{P}=0.160)$. The genotype frequencies for 1298AA and 1298CC did not differ from controls in children with NTDs and their mothers $(\mathrm{P}=0.551$ and $\mathrm{P}=0.062$, respectively). On the other hand, the 1298AC genotype frequencies in children with NTDs and their mothers were significantly different from the healthy controls $(\mathrm{P}=0.025)$. The genotype frequency for 1298AC was lower in children with NTDs than controls. Moreover, there was not a significant association between clinical distribution of NTDs and the 1298AA/AC/CC genotypes $(\mathrm{P}>0.05)$ (Table 2). Serum folate, vitamin B12 and homocysteine levels in groups were analyzed and it was found that serum vitamin B12 concentrations were higher in children with NTDs than in their mothers and controls $(P=0.001)$. Serum homocysteine and folate levels were not significantly different in children with NTDs and their mothers in comparison to the controls $(\mathrm{P}=0.494$ and $\mathrm{P}=0.141$, respectively; Table 3$)$. Furthermore, we evaluated the effect of the 1298AC genotype on serum folate, vitamin B12, and homocysteine levels in children with NTDs. There was no significant difference in serum folate, vitamin B12, and homocysteine levels between 1298AA, 1298AC and 1298CC genotypes in the children with NTDs group (data not shown).

Table 2. MTHFR A1298C genotype and allele frequencies.

\begin{tabular}{l|c|c|c|c|c}
\hline \multirow{2}{*}{ Group (N) } & \multicolumn{3}{|c|}{ Genotype frequencies [\% (N)] } & \multicolumn{2}{c}{ Allele frequencies [\% (N)] } \\
\cline { 2 - 6 } & AA & AC & CC & A & C \\
\hline NTD Cases (33) & $45.5(15)$ & $6.0(2)$ & $48.5(16)$ & $48.5(32)$ & $51.5(34)$ \\
\hline Mothers (26) & $50(13)$ & $30.8(8)$ & $19.2(5)$ & $65.4(34)$ & $36.4(18)$ \\
\hline Controls (48) & $37.5(18)$ & $29.2(14)$ & $33.3(16)$ & $52.1(50)$ & $47.9(46)$ \\
\hline
\end{tabular}

$\mathrm{NTD}=$ neural tube defects.

Table 3. Serum folate (S-folate), vitamin B12 (vit B12), and homocysteine (Hcy) levels in study groups.

\begin{tabular}{l|c|c|c|c}
\hline & NTD cases (means \pm SD) & Mothers (means \pm SD) & Controls (means \pm SD) & P value \\
\hline S-folate $(\mathrm{ng} / \mathrm{mL})$ & $13.22 \pm 2.20$ & $12.06 \pm 2.50$ & $13.15 \pm 2.66$ & 0.141 \\
\hline vit B12 $(\mathrm{pg} / \mathrm{mL})$ & $408.82 \pm 217.26$ & $281.73 \pm 98.79$ & $292.73 \pm 110.58$ & 0.001 \\
\hline Hcy $(\mu \mathrm{M})$ & $9.66 \pm 3.32$ & $10.66 \pm 3.83$ & $10.31 \pm 3.07$ & 0.494 \\
\hline
\end{tabular}

\section{DISCUSSION}

The MTHFR A1298C polymorphism is a missense mutation consisting of a nucleotide transition $(1298 \mathrm{~A} \rightarrow \mathrm{C})$, which results in a glutamate to alanine substitution (van der Put et al., 1998). In this study, we analyzed the genotype distribution and allele frequencies of the MTHFR gene A1298C polymorphism in children with NTDs, their mothers, and healthy controls in Turkey. This present study indicates that $\mathrm{A}$ and $\mathrm{C}$ allele frequencies in children with NTDs and their mothers were similar to what is observed in controls. On the other hand, the 1298AC genotype frequencies in children with NTDs and their mothers were significantly different from the controls. This result cannot be considered as a risk factor because the analysis of the 1298AA and 1298CC genotype frequencies showed similar distribution in children with NTDs and their mothers compared to controls. Similarly, Haggarty et al. (2008) reported that the frequency of the 1299CC genotype was essentially the same in the children and their mothers (9.0 and 9.1\%, respectively). Furthermore, Cunha et al. (2002) could not find a direct association between the A1298C polymorphism and occurrence of NTDs. ParleMcDermott et al. (2003) reported that case-control comparisons and log linear analysis did 
not reveal an association between the A1298C polymorphism and occurrence of NTDs. Data from Europe and the Hispanic population of the USA showed no difference in the A1298C polymorphism between patients with NTDs and the controls (Stegmann et al., 1999; van der Put and Blom, 2000; Volcik et al., 2000). In contrast, Boduroğlu et al. (1999) concluded that the MTHFR 1298AC polymorphism might be a risk factor for the occurrence of NTDs in the Turkish population although it is not statistically significant. De Marco et al. (2002) suggested that the MTHFR A1298C polymorphism is a genetic determinant for NTD risk in Italy. Also, Weisberg et al. (1998) reported an association between the A1298C polymorphism and NTD risk. Lesion distribution of NTDs was similar between the genotypes of all three groups in our study. Samson (2003) did not find any statistically significant association between the lesion distribution of NTDs in the consanguineous and non-consanguineous populations. Serum folate and homocysteine levels in our study were not different between groups. Hanson et al. (2001) also demonstrated that there was no effect of the A1298C polymorphism on homocysteine metabolism. Homozygosity for the 1298 MTHFR polymorphism (1298CC) does result in decreased enzyme activity but this polymorphism is not associated with elevated homocysteine levels or with an increased risk for NTD in offspring (van der Put and Blom, 2000). Similarly, individuals who are either heterozygous (1298AC) or homozygous (1298CC) for the polymorphism showed decreased enzyme activity although their plasma homocysteine levels were not altered significantly (van der Put et al., 1998; Weisberg et al., 1998).

In our study, mothers of children with NTDs had significantly lower vitamin B12 levels than other groups. Vitamin B12 is a nutritional factor and its deficiency may affect the development of NTDs in offspring. It has been reported that low vitamin B12 concentrations could lead to reduced methylation of homocysteine to methionine, enhancing the impairment of folate metabolism and increasing the risk for development of NTDs (van der Put and Blom, 2000). It has also been reported that the combination of MTHFR polymorphisms and low folate and vitamin B12 intake is associated with a greater risk for NTDs than each variable alone, indicating a strong genetic-nutritional interaction (Molloy et al., 1998; Stegmann et al., 1999). Cunha et al. (2002) reported that the mutant $C$ allele was not associated with differences in folate and vitamin B12 concentrations in children with NTDs. Furthermore, the same researchers found higher concentrations of homocysteine in children with NTDs who have the 1289AA MTHFR genotype. It is reported that neither the homozygous nor heterozygous genotypes for the 1298AC polymorphism are associated with higher homocysteine nor lower plasma folate levels, although the 1298AC polymorphism has a significant effect on the activity of MTHFR (van der Put et al., 1998). Fifty to seventy percent of all NTDs could be prevented by periconceptional folic acid supplementation (Posey et al., 1996). This suggests that polymorphisms in the MTHFR gene or other genes involved in folate pathways and low nutritional folate or vitamin B12 intake might have roles in risk of NTDs. van der Put and Blom (2000) suggested that the A1298C MTHFR polymorphism may play a secondary role for risk of NTDs. Conflicting results exist regarding the association of the A1298C polymorphism in MTHFR and NTD risk. One explanation for this controversy might be that alleles are differently distributed among various populations (Gonzalez-Herrera et al., 2007).

We did not demonstrate an association between the MTHFR gene A1298C polymorphism and NTD risk in our study group. Moreover, the MTHFR gene A1298C polymorphism does not affect folic acid, vitamin B12 or homocysteine metabolism in Turkish children with NTDs. Low serum vitamin B12 levels in mothers of children with NTDs may be associated with their nutritional status. Maternal folate and vitamin B12 status during the 
periconceptional period may be critical for the development of NTDs, and our data support the hypothesis of the multifactorial etiology of NTDs involving the combination of both genetic and nutritional factors.

\section{Conflicts of interest}

The authors declare no conflict of interest.

\section{ACKNOWLEDGMENTS}

Research supported by the Kocatepe University Scientific Research Committee as project number 051.TIP.40. The authors also wish to thank Afyon Kocatepe University's Foreign Language Support Unit for language editing.

\section{REFERENCES}

Afman LA, Blom HJ, Drittij MJ, Brouns MR, et al. (2005). Inhibition of transmethylation disturbs neurulation in chick embryos. Brain Res. Dev. Brain Res. 158: 59-65.http://dx.doi.org/10.1016/j.devbrainres.2005.06.002

Aydinli K, Cagdas A, Kayserili H, Kuseyri F, et al. (1998). The effect of preconceptional folic acid treatment on the recurrence risk of nonsyndromic neural tube defects. Balkan J. Med. Genet. 1: 120-124.

Barber RC, Lammer EJ, Shaw GM, Greer KA, et al. (1999). The role of folate transport and metabolism in neural tube defect risk. Mol. Genet. Metab. 66: 1-9.http://dx.doi.org/10.1006/mgme.1998.2787

Blom HJ, Shaw GM, den Heijer M and Finnell RH (2006). Neural tube defects and folate: case far from closed. Nat. Rev. Neurosci. 7: 724-731. http://dx.doi.org/10.1038/nrn1986

Boduroğlu K, Alikaşifoğlu M, Anar B and Tunçbilek E (1999). Association of the 677C - > T mutation on the methylenetetrahydrofolate reductase gene in Turkish patients with neural tube defects. J. Child Neurol. 14: 159-161. http://dx.doi.org/10.1177/088307389901400305

Boyles A, Hammock P and Speer M (2005). Candidate gene analysis in human neural tube defects. Am. J. Med. Genet. Part C 135C: 9-23.

Christianson A (2006). Global report on birth defects. Published by March of Dimes Birth Defects Foundation, White Plains, NY, USA.

Copp AJ, Brook FA, Estibeiro JP, Shum AS, et al. (1990). The embryonic development of mammalian neural tube defects. Prog. Neurobiol. 35: 363-403.http://dx.doi.org/10.1016/0301-0082(90)90037-H

Cunha AL, Hirata MH, Kim CA, Guerra-Shinohara EM, et al. (2002). Metabolic effects of C677T and A1298C mutations at the MTHFR gene in Brazilian children with neural tube defects. Clin. Chim. Acta 318: 139-143. http://dx.doi. org/10.1016/S0009-8981(01)00764-1

Czeizel AE and Dudás I (1992). Prevention of the first occurrence of neural-tube defects by periconceptional vitamin supplementation. $N$. Engl. J. Med. 327: 1832-1835.http://dx.doi.org/10.1056/NEJM199212243272602

De Marco P, Moroni A, Merello E, de Franchis R, et al. (2000). Folate pathway gene alterations in patients with neural tube defects. Am. J. Med. Genet. 95: 216-223. http://dx.doi.org/10.1002/1096-8628(20001127)95:3<216::AID$\underline{\text { AJMG6 }>3.0 . \mathrm{CO} ; 2-\mathrm{F}}$

De Marco P, Calevo MG, Moroni A, Arata L, et al. (2002). Study of MTHFR and MS polymorphisms as risk factors for NTD in the Italian population. J. Hum. Genet. 47: 319-324. http://dx.doi.org/10.1007/s100380200043

Dunlevy LPE, Burren KA, Mills K, Chitty LS, et al. (2006). Integrity of the methylationcycle is essential for mammalian neural tube closure. Birth Defects Res. Part A 76: 544-552.

Eskes TK (1998). Neural tube defects, vitamins and homocysteine. Eur. J. Pediatr. 157 (Suppl 2): S139-S141.http:// dx.doi.org/10.1007/PL00014299

Gonzalez-Herrera L, Castillo-Zapata I, Garcia-Escalante G and Pinto-Escalante D (2007). A1298C polymorphism of the MTHFR gene and neural tube defects in the state of Yucatan, Mexico. Birth Defects Res. Part A 79: 622-626.

Haggarty P, Campbell DM, Duthie S, Andrews K, et al. (2008). Folic acid use in pregnancy and embryo selection. BJOG 115: 851-856. http://dx.doi.org/10.1111/j.1471-0528.2008.01737.x

Hanson NQ, Aras O, Yang F and Tsai MY (2001). C677T and A1298C polymorphisms of the methylenetetrahydrofolate reductase gene: incidence and effect of combined genotypes on plasma fasting and post-methionine load homocysteine in vascular disease. Clin. Chem. 47: 661-666. 
Molloy AM, Mills JL, Kirke PN, Ramsbottom D, et al. (1998). Low blood folates in NTD pregnancies are only partly explained by thermolabile 5,10-methylenetetrahydrofolate reductase: low folate status alone may be the critical factor. Am. J. Med. Genet. 78: 155-159. http://dx.doi.org/10.1002/(SICI)1096-8628(19980630)78:2<155::AIDAJMG11>3.0.CO;2-M

MRC Vitamin Study Research Group (1991). Prevention of neural tube defects: results of the Medical Research Council Vitamin Study. Lancet 338: 131-137. http://dx.doi.org/10.1016/0140-6736(91)90133-A

Parle-McDermott A, Mills JL, Kirke PN, O’Leary VB, et al. (2003). Analysis of the MTHFR 1298A->C and 677C->T polymorphisms as risk factors for neural tube defects. J. Hum. Genet. 48: 190-193. http://dx.doi.org/10.1007/s10038003-0008-4

Perez AB, D’Almeida V, Vergani N, de Oliveira AC, et al. (2003). Methylenetetrahydrofolate reductase (MTHFR): incidence of mutations C677T and A1298C in Brazilian population and its correlation with plasma homocysteine levels in spina bifida. Am. J. Med. Genet. A. 119A: 20-25.http://dx.doi.org/10.1002/ajmg.a.10059

Posey DL, Khoury MJ, Mulinare J, Adams MJ, Jr., et al. (1996). Is mutated MTHFR a risk factor for neural tube defects? Lancet 347: 686-687. http://dx.doi.org/10.1016/S0140-6736(96)91236-2

Samson GR (2003). The incidence and demography of neural tube defects in Abu Dhabi, United Arab Emirates (19921999). J. Trop. Pediatr. 49: 256-257. http://dx.doi.org/10.1093/tropej/49.4.256

Stegmann K, Ziegler A, Ngo ET, Kohlschmidt N, et al. (1999). Linkage disequilibrium of MTHFR genotypes 677C/T$1298 \mathrm{~A} / \mathrm{C}$ in the German population and association studies in probands with neural tube defects(NTD). Am. J. Med. Genet. 87: 23-29. http://dx.doi.org/10.1002/(SICI)1096-8628(19991105)87:1<23::AID-AJMG5>3.0.CO;2-E

Tunçbilek E, Boduroğlu K and Alikaşifoğlu M (1999). Neural tube defects in Turkey: prevalence, distribution and risk factors. Turk. J. Pediatr. 41: 299-305.

van der Linden IJ, Heil SG, van Egmont Petersen M, van Straaten HW, et al. (2008). Inhibition of methylation and changes in gene expression in relation to neural tube defects. Birth Defects Res. Part A 82: 676-683.

van der Put NM and Blom HJ (2000). Neural tube defects and a disturbed folate dependent homocysteine metabolism. Eur. J. Obstet. Gynecol. Reprod. Biol. 92: 57-61.http://dx.doi.org/10.1016/S0301-2115(00)00426-7

van der Put NM, Gabreels F, Stevens EMB, Smeitink JA, et al. (1998). Blom HJ: A second common mutation in the methylenetetrahydrofolate reductase gene: a risk factor for neural tube defects? Am. J. Hum. Genet. 62: 1044-1051. http://dx.doi.org/10.1086/301825

Volcik KA, Blanton SH, Tyerman GH, Jong ST, et al. (2000). Methylenetetrahydrofolate reductase and spina bifida: evaluation of level of defect and maternal genotypic risk in Hispanics. Am. J. Med. Genet. 95: 21-27.http://dx.doi. org/10.1002/1096-8628(20001106)95:1<21::AID-AJMG6>3.0.CO;2-M

Weisberg I, Tran P, Christensen B, Sibani S, et al. (1998). A second common mutation in the methylenetetrahydrofolate reductase associated with decreased enzyme activity. Mol. Genet. Metab. 64: 169-172. http://dx.doi.org/10.1006/ mgme.1998.2714 